\title{
Notch 1 is a valuable therapeutic target against cell survival and proliferation in clear cell renal cell carcinoma
}

\author{
ZHIMING ZHUANG ${ }^{1}$, JIANGUI LIN ${ }^{1}$, YIQUN HUANG ${ }^{2}$, TIANQI LIN ${ }^{1}$, ZHOUDA ZHENG $^{1}$ and XUDONG MA ${ }^{2}$ \\ Departments of ${ }^{1}$ Urology and ${ }^{2}$ Hematology, Zhangzhou Affiliated Hospital of Fujian Medical University, \\ Zhangzhou, Fujian 363000, P.R. China
}

Received December 8, 2015; Accepted May 11, 2017

DOI: $10.3892 / \mathrm{ol} .2017 .6587$

\begin{abstract}
Notch 1 is a key component of the Notch pathway, which performs a crucial role in clear cell renal cell carcinoma (CCRCC) development. The present study aimed to investigate whether Notch 1 could serve as a potential target for CCRCC treatment. Firstly, an association analysis was performed using 52 CCRCC cases and 30 normal controls. The results indicated that Notch 1 protein expression in renal tissues was closely associated with the incidence of CCRCC. In addition, higher Notch 1 expression in CCRCC tissues was positively associated with higher tumor-node-metastasis stage and Fuhrman grade, in addition to larger tumor size. Subsequently, an in vitro study was conducted to examine the biological functions of Notch 1 in CCRCC 786-O cells through inhibiting the Notch 1 expression with Notch 1-specific small interfering RNA (siRNA). As a result, the inhibition of Notch 1 expression by increasing concentrations of Notch 1-specific siRNA dose-dependently decreased cell proliferation and increased cell apoptosis in 786-O cells. Furthermore, B-cell lymphoma-2 and procaspase-3 expression exhibited a dose-dependent decrease accompanied with a dose-dependent inactivation of the Akt/mammalian target of rapamycin (mTOR) signaling pathway in Notch 1 siRNA-treated 786-O cells. These findings demonstrated that Notch 1 was associated with CCRCC carcinogenesis and progression, the underlying mechanism of which was that Notch 1 acted as an activator for cell proliferation and a suppressor for cell apoptosis through the Akt/mTOR signaling-dependent pathway in CCRCC. In conclusion, the
\end{abstract}

Correspondence to: Professor Xudong Ma, Department of Hematology, Zhangzhou Affiliated Hospital of Fujian Medical University, 59 Shengli Road, Zhangzhou, Fujian 363000, P.R. China E-mail: maxudong006@hotmail.com

Dr Zhouda Zheng, Department of Urology, Zhangzhou Affiliated Hospital of Fujian Medical University, 59 Shengli Road, Zhangzhou, Fujian 363000, P.R. China

E-mail: zhouda_u@sina.com

Key words: clear cell renal cell carcinoma, Notch 1, association analysis, therapeutic target, molecular mechanism present study confirmed that Notch 1 is a valuable target against cell survival and proliferation in CCRCC treatment.

\section{Introduction}

Renal cell carcinoma (RCC), which originates from the epithelium of renal parenchyma uriniferous tubule, is one of the most commonly occurring types of cancer in the world $(1,2)$. Each year, >240,000 new cases are diagnosed and >100,000 RCCassociated mortalities occur (2). The majority of cases of RCC $(\sim 75 \%)$ are clear cell RCC (CCRCC) (3). Currently, nephrectomy remains the mainstay of CCRCC therapy, but $\sim 20 \%$ of patients treated with nephrectomy are subject to recurrence and metastasis (4). Patients with metastatic CCRCC usually have a poor prognosis and obtain little benefit from conventional chemoradiotherapy.

In previous years, targeted therapy has been developed as a promising approach against metastatic advanced-stage CCRCC (5-7). The key to targeted therapy is to identify the crucial molecular targets that usually mediate aberrant signaling pathways in carcinogenesis and tumor progression. The Notch signaling pathway performs a pivotal role in the regulation of cell proliferation, differentiation and apoptosis (3). The four mammalian Notch receptors, termed Notch 1-4, are the key components of the Notch pathway (3). Notch receptors receive signals from cell surface-tethered ligands (including Delta-like 1, 3 and 4, and Jagged 1 and 2) on neighboring cells through specific binding (3), and then induce a two-step proteolytic cleavage by which the Notch intracellular domain is released to activate the transcription of downstream target genes in the nucleus (8). Dysregulation of the Notch signaling pathway has been demonstrated to be associated with multiple types of human cancer, including CCRCC (9). One of the most frequently detected members of the Notch receptor family in tumor tissues is Notch 1, and its overexpression can promote cancer genesis through multiple processes such as cell growth and apoptosis (10-12). Therefore, Notch 1 may be a potential target for CCRCC therapy.

On this basis, in the present study, an association analysis based on 52 CCRCC cases and 30 normal controls was performed to investigate the association between Notch 1 protein expression and CCRCC development. The important role Notch 1 performs in CCRCC cell proliferation and apoptosis was then confirmed through silencing Notch 1 expression 
in human CCRCC 786-O cells with Notch 1-specific small interfering RNA (siRNA), and the underlying mechanisms were elucidated in vitro.

\section{Materials and methods}

Subject recruitment and sample collection. Patients who received curative surgical resection for primary renal tumors at the Department of Surgery of Zhangzhou Affiliated Hospital of Fujian Medical University (Fujian, China) between October 2005 and April 2012 were recruited. Patients were eligible for the present study if they were diagnosed as CCRCC by the postoperative pathological analysis and had not received chemotherapy, radiotherapy and immunotherapy prior to surgery. Finally, a total of 52 CCRCC cases (age, 24-81; 34 male and 18 female) were included in the present study. Pathological stage of each case was evaluated according to the tumor-node-metastasis (TNM) classification (13) and Fuhrman grade (14). Detailed clinical data of the cases are presented in Table I. Renal tumor and pericarcinoma tissue samples were obtained from surgically removed tissues of the 52 patients. A total of 30 normal renal tissue samples were collected as control samples from other patients who underwent surgical resection for trauma. Informed consent was obtained from all individual patients included in the present study. The present study was reviewed and approved by the Ethics Committee of Zhangzhou Affiliated Hospital of Fujian Medical University (Fujian, China).

Tissue microarray and immunohistochemistry (IHC) assays. The tissue microarray was constructed according to our previous description (15). Briefly, target tissue cores were obtained from donor paraffin blocks and then arranged in a new recipient paraffin block (tissue array block), which was subsequently sectioned into numerous thin slices with a thickness of $4 \mu \mathrm{m}$ for each section. Tissue sections were randomly selected and attached to the L-lysine-treated glass slides for IHC assays, which were processed by utilizing the UltraSensitive ${ }^{\mathrm{TM}}$ S-P kit (Maixin-Bio Co., Ltd., Fuzhou, China) according to the manufacturer's protocol. These sections were blocked with normal goat serum (Maixin-Bio Co., Ltd.) for $20 \mathrm{~min}$ at room temperature. IHC staining of sections was performed with the primary antibody rabbit anti-human polyclonal antibody to Notch 1 (cat. no. N4788; dilution, 1:200; Sigma-Aldrich; Merck KGaA, Darmstadt, Germany). Sections treated with PBS instead of the primary antibody were used as the negative controls, and purchased positive tissue sections (Maixin-Bio Co., Ltd.) were used as the positive controls. In this process, 3,3-diaminobenzidene (DAB) was employed as the stain to treat sections for 3-15 min at room temperature. Brown yellow staining indicated the positive Notch 1 expression. Cells with light or brown yellow staining particles in the cytomembrane or cytoplasm were the positive cells. A semi-quantitative scoring system (Olympus BX41, magnification, x200; Olympus Co., Tokyo, Japan) was employed to evaluate the IHC results. Scoring for color density and percentage of stained cells constituted the basis of the evaluation system. Color density was scored as follows: No staining, 0 ; slight staining, 1; moderate staining, 2; and strong staining, 3 . With regard to scoring for percentage of stained
Table I. Characteristics of patients with clear cell renal cell carcinoma included in the present study.

\begin{tabular}{lc}
\hline Characteristics & Patients, $\mathrm{n}(\%)$ \\
\hline Sex & \\
Male & $34(65.4)$ \\
Female & $18(34.6)$ \\
Age, range (mean \pm standard deviation) & $24-81(55.5 \pm 13.9)$ \\
$<60$ years & $32(61.5)$ \\
$\geq 60$ years & $20(38.5)$ \\
Tumor-node-metastasis stage & \\
I+II & $33(63.5)$ \\
III+IV & $19(36.5)$ \\
Fuhrman grade & \\
$1+2$ & $35(67.3)$ \\
$3+4$ & $17(32.7)$ \\
Tumor size & $16(30.8)$ \\
$<5.0 \mathrm{~cm}$ & $36(69.2)$ \\
$\geq 5.0 \mathrm{~cm}$ &
\end{tabular}

cells, $0,<50,50-75$ and $>75 \%$ cells staining were scored as $0,1,2$ and 3 , respectively. The sum value of the two scores $0,1-2,3-4$ or 5-6 were further scored as,,-+++ and +++ , respectively. The symbol - was considered as negative; + and ++ indicated low expression of Notch 1 protein, while +++ indicated high expression.

Cells and cell culture. The CCRCC 786-O cell line was purchased from the Shanghai Cell Bank of Chinese Academy of Sciences (Shanghai, China) and maintained in RPMI-1640 medium (Gibco; Thermo Fisher Scientific, Inc., Waltham, MA, USA) containing 15\% fetal bovine serum (Gibco; Thermo Fisher Scientific, Inc.), $100 \mathrm{U} / \mathrm{ml}$ penicillin and $100 \mu \mathrm{g} / \mathrm{ml}$ streptomycin in an atmosphere with saturation humidity and $5 \% \mathrm{CO}_{2}$ at $37^{\circ} \mathrm{C}$. Cells grew as a monolayer and adhered to the wall, being regularly passaged every 2-3 days. Cells in the logarithmic phase were used in subsequent experiments.

RNA interference. RNA interference was employed to silence the expression of Notch 1 in 786-O cells. The siRNA targeted to human Notch 1 gene was designed referring to the principles described in previous studies (16-19). The Notch 1-specific siRNA sequences were 5'-GCAGCUGCACUUCAUGUA CGU-3' (sense) and 5'-CGUCGACGUGAAGUACAUGCA-3' (antisense). A nonspecific control siRNA whose sequences were 5'-UUCUCCGAACGUGUCACGUTT-3' (sense) and 5'-ACGUGACACGUUCGGAGAATT-3' (antisense) was also designed. The siRNAs were synthesized by Shanghai Gene Pharma Co., Ltd. (Shanghai, China). Transfection assays were performed utilizing Lipofectamine ${ }^{\circledR} 2000$ (Invitrogen; Thermo Fisher Scientific, Inc.) following the manufacturer's protocol. The prepared $786-\mathrm{O}$ cells $\left(1 \times 10^{5} /\right.$ well) were seeded on 24-well plates and transfected with the non-specific control siRNA and the Notch 1-specific siRNA (40, 80 and $120 \mathrm{nmol} / \mathrm{l})$. Transfection efficiency was measured using the parallel transfection 
of a random sequence marked with green fluorescence; the transfection efficiency was calculated after $6 \mathrm{~h}$ of transfection by the formula: Transfection efficiency $=$ the count of cells with fluorescence (positive)/the count of total cells.

Reverse transcription-polymerase chain reaction (RT-PCR) assays. At $24 \mathrm{~h}$ post-transfection, 786-O cells in each group were harvested and washed with $0.02 \mathrm{M}$ PBS ( $\mathrm{pH}$ 7.4). Total RNA of these cells was extracted using TRIzol reagent (Invitrogen; Thermo Fisher Scientific, Inc.) according to the manufacturer's protocol. The acquired RNA precipitate was redissolved by 20-24 $\mu 1$ sterile deionized water and its concentration was determined using a UV2100 spectrophotometer (Shanghai Puxi Instrument Co., Ltd., Shanghai, China). The complementary DNA (cDNA) was synthesized in a $25 \mu \mathrm{l}$ mixture containing $0.4 \mu \mathrm{g}$ total RNA, $1.0 \mu \mathrm{l}$ oligo (dT) primer, $5.0 \mu 15 \mathrm{X}$ reaction buffer, $2.0 \mu \mathrm{l} \mathrm{dNTP} \operatorname{mix}(10 \mathrm{mM}), 1.0 \mu \mathrm{l}$ RNasin, $1.0 \mu \mathrm{l}$ avian myeloblastosis virus (AMV) reverse transcriptase $(20 \mathrm{U} / \mu \mathrm{l})$ and diethyl pyrocarbonate-treated water, at $42^{\circ} \mathrm{C}$ for $30 \mathrm{~min}$. At the end of synthesis, the mixture was incubated at $99^{\circ} \mathrm{C}$ for $5 \mathrm{~min}$ to inactivate the AMV reverse transcriptase. Subsequently, the synthesized cDNA was used as the template to amplify Notch 1 , and $\beta$-actin was used as the internal control. Primers of Notch 1 and $\beta$-actin were designed utilizing Primer 5.0 (Premier Biosoft International, Palo Alto, CA, USA). The primer sequences were as follows: Notch 1 forward, 5'-CCGTCATCTCCGACTTCATC-3' and reverse, 5'-GGACTTGCCCAGGTCATCTAC-3'; $\beta$-actin forward, 5'-CTCGTCATACTCCTGCTTGCT-3' and reverse, 5'-CGGGACCTGACTGACTACCTC-3'. The PCR amplification system contained 5.0 $\mu \mathrm{l}$ 10X PCR buffer, $4.0 \mu \mathrm{l} \mathrm{dNTP}$ Mix (10 mM), $2.0 \mu \mathrm{l}$ of each primer, $1.0 \mu \mathrm{l}$ cDNA, $1.0 \mu 1 \mathrm{Taq}$ DNA polymerase (Invitrogen; Thermo Fisher Scientific, Inc.)

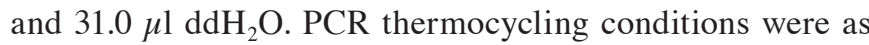
follows: $5 \mathrm{~min}$ pre-degeneration at $95^{\circ} \mathrm{C}, 45 \mathrm{~min}$ thermal-cycle program, including 30 cycles of $95^{\circ} \mathrm{C}$ for $30 \mathrm{sec}, 58^{\circ} \mathrm{C}$ for $30 \mathrm{sec}$ and $72^{\circ} \mathrm{C}$ for $30 \mathrm{sec}$, and $10 \mathrm{~min}$ extension at $72^{\circ} \mathrm{C}$. PCR products were separated by $1.5 \%$ agarose gel electrophoresis supplemented with ethidium bromide (cat. no. sc-286960; Santa Cruz Biotechnology, Inc.) for visualization, and semi-quantified using the GelDocEZ system (Bio-Rad Laboratories, Inc., Hercules, CA, USA).

Western blot analysis. At $24 \mathrm{~h}$ post-transfection, 786-O cells were harvested. Subsequent to washing twice with cooled TBS solution, $1 \times 10^{6}$ cells were mixed with $100 \mu 1$ lysis buffer (included in MicroRoto for cell lysis and protein extraction kit; Bio-Rad Laboratories, Inc.) and $1 \mu 1$ enzyme inhibitor, and incubated at $4^{\circ} \mathrm{C}$ for $30 \mathrm{~min}$ to obtain lysate. Following centrifugation at $12,000 \mathrm{x}$ g for $10 \mathrm{~min}$ at $10^{\circ} \mathrm{C}$, the supernatant of the lysate in the middle layer was collected and total protein content of each collected lysate sample was determined by Bradford method. Subsequently, proteins were separated on a $12 \%$ SDS-PAGE gel and blotted to nitrocellulose (NC) membranes. The NC membranes were blocked with the $0.02 \mathrm{M}$ TBS buffer ( $\mathrm{pH}$ 7.4) containing 5\% skimmed milk for $60 \mathrm{~min}$ at $37^{\circ} \mathrm{C}$, and then probed with specific primary antibodies, including mouse anti-human monoclonal antibodies of Notch 1 (cat. no. sc-71719; dilution, 1:400; Santa Cruz Biotechnology, Inc., Dallas, TX, USA), B-cell lymphoma-2
(Bcl-2; cat. no. sc-23960; dilution, 1:500; Santa Cruz Biotechnology, Inc.) and procaspase-3 (cat. no. sc-271028; dilution, 1:500; Santa Cruz Biotechnology, Inc.), and rabbit anti-human polyclonal antibodies of RAC-alpha serine/threonine-protein kinase (Akt; cat. no. 14702; dilution, 1:500; Cell Signaling Technology, Inc., Danvers, MA, USA), phosphorylated (p)-Akt (cat. no. 13461; dilution, 1:250; Cell Signaling Technology, Inc.), p-mammalian target of rapamycin (mTOR) (cat. no. 5536; dilution, 1:400; Cell Signaling Technology, Inc.), p-P70S6K (cat. no. 9862; dilution, 1:500; Cell Signaling Technology, Inc.) and $\beta$-actin (cat. no. sc-81760; dilution, 1:2,500; Santa Cruz Biotechnology, Inc.) following the manufacturer's protocol. All the incubations with primary antibodies were maintained at $37^{\circ} \mathrm{C}$ for $60 \mathrm{~min}$. Subsequent to washing with TBST, the membranes were incubated with corresponding secondary antibodies, including goat anti-mouse (cat. no. sc-362267; dilution, 1:5,000-7,500; Santa Cruz Biotechnology, Inc.) and goat anti-rabbit antibodies (cat. no. sc-2040; dilution, 1:5,000-7,500; Santa Cruz Biotechnology, Inc.) for $60 \mathrm{~min}$ at $37{ }^{\circ} \mathrm{C}$, followed by incubation with enhanced chemiluminescence reagent (Santa Cruz Biotechnology, Inc.). Finally, target protein content was determined by assessing chemiluminescence with AlphaDigiDoc imaging analysis system (version 7.1; Alpha Innotec, Kasendorf, Germany). Each experiment was repeated three times.

Cell proliferation analysis. 786-O cells were seeded on 96-well plates $\left(1 \times 10^{5}\right.$ cells/well) and then transfected with negative control siRNA and Notch 1 siRNA (40, 60, 80, 100 and $120 \mathrm{nmol} / \mathrm{l}$ ). Cell proliferation was detected by MTT assays. Briefly, at $24 \mathrm{~h}$ post-transfection, 786-O cells in each well were treated with $10 \mu \mathrm{l}$ MTT $(5 \mathrm{mg} / \mathrm{ml}$; Sigma-Aldrich; Merck $\mathrm{KGaA}$ ) and incubated for an additional $4 \mathrm{~h}$ at $37^{\circ} \mathrm{C}$. At the end of incubation, the plates were centrifuged at $800 \mathrm{x} \mathrm{g}$ for $5 \mathrm{~min}$ at room temperature and the supernatant was removed. Following the addition of $100 \mu 1$ dimethyl sulfoxide (Sigma-Aldrich; Merck KGaA) in each well, cells were detected on a microplate reader Stat Fax-2100 (Awareness Technologies, Westport, CT, USA) at a dual-wavelength of 492 and $630 \mathrm{~nm}$, and cell proliferation rate was calculated according to the formula: Cell proliferation rate $(\%)=\left(\mathrm{A}_{\text {experi- }}\right.$ ment $\left.-A_{\text {blank }}\right) /\left(A_{\text {control }}{ }_{\text {Ablank }}\right)$. Each sample in these assays was performed in triplicate.

Apoptosis assays. Cell apoptosis was investigated by terminal deoxynucleotidyl-transferase-mediated dUTP nick end labeling (TUNEL) assays using an in situ cell death detection kit (Promega Corporation, Madison, WI, USA) according to the manufacturer's protocol. In brief, following treatment with control siRNA and Notch 1 siRNA (40, 80 and $120 \mathrm{nmol} / \mathrm{l})$, $786-\mathrm{O}$ cells were washed and dried in air. Cells $\left(5 \times 10^{4}\right)$ were then fixed with $4 \%$ paraformaldehyde supplemented in PBS at room temperature for $25 \mathrm{~min}$. Subsequent to washing twice with PBS, cells were incubated with $0.2 \%$ Triton X-100 PBS for $5 \mathrm{~min}$ at room temperature, followed by 5-10 $\mathrm{min}$ incubation with equilibration buffer (Invitrogen; Thermo Fisher Scientific, Inc.) at room temperature. Subsequently, TUNEL reaction solution was added to each sample and incubated at $37^{\circ} \mathrm{C}$ for $60 \mathrm{~min}$. When reaction was terminated, samples were immersed in $0.3 \% \mathrm{H}_{2} \mathrm{O}_{2}$ for 3-5 min and then rinsed 
with PBS. Following the addition of horseradish peroxidase diluted with PBS, the samples were incubated at room temperature for $30 \mathrm{~min}$. Finally, samples were incubated with 3,3'-diaminobenzidine mixture till light brown appeared in the background. Subsequent to rinsing with deionized water, samples were observed under a microscope (Olympus BX41; magnification, x200). Three fields of view were selected for each sample. Apoptotic rate was calculated as follows: Apoptotic rate $(\%)=$ number of apoptotic cells/number of total cells. Experiments were repeated in triplicate.

Statistical analysis. Statistical analyses were performed using SPSS version 11.5 software (SPSS, Inc., Chicago, IL, USA). Association analysis between Notch 1 protein expression and CCRCC was performed with $\chi^{2}$ test. For other analysis, comparison among three or more groups was performed by one-way analysis of variance, followed by Student-Newman-Keuls post-hoc test for comparison between two groups. Measurement data are presented as the mean \pm standard deviation. $\mathrm{P}<0.05$ was considered to indicate a statistically significant difference.

\section{Results}

Notch 1 protein expression is positively associated with CCRCC carcinogenesis and progression. Tissue samples obtained from 52 cases were eligible for the present study and tissue microarrays were successfully constructed with the exception of 5 pericarcinoma tissue samples. IHC and association analyses suggested that Notch 1 protein expression was positive in $82.7 \%$ of CCRCC tumor tissues, and the positive incidence was significantly higher compared with that in pericarcinoma $(42.6 \% ; \mathrm{P}<0.01)$ and normal $(16.7 \%$; $\mathrm{P}<0.01)$ renal tissues (Table II). Additional analysis indicated that high expression of Notch 1 protein was associated with TNM stage $\left(\chi^{2}=6.267 ; \mathrm{P}<0.05\right)$, Fuhrman grade $\left(\chi^{2}=7.90 ; \mathrm{P}<0.01\right)$ and tumor size $\left(\chi^{2}=4.160 ; \mathrm{P}<0.05\right)$, but not associated with sex $\left(\chi^{2}=0.036 ; \mathrm{P}>0.05\right)$ and age $\left(\chi^{2}=0.054 ; \mathrm{P}>0.05\right)$ (Table III) Representative IHC results are presented in Fig. 1. Therefore, Notch 1 protein expression was closely associated with CCRCC carcinogenesis and progression.

siRNA against Notch 1 interferes with Notch 1 expression in CCRCC 786-O cells. The effectiveness of the transfections was evaluated by transfection efficiency, which was determined by the rate of positive cells to total cells in the parallel transfection group. Positive cells with green fluorescence and total cells at the same visual field (Fig. 2A) were counted under an inverted fluorescence microscope after $6 \mathrm{~h}$ of transfection. The transfection efficiency was $32.6 \pm 4.8 \%$, indicating the success of the interference assays. At $24 \mathrm{~h}$ post-transfection, mRNA and protein expression of Notch 1 in 786-O cells was detected by RT-PCR and western blot analysis, respectively, to confirm the interfering effect of siRNAs against Notch 1. As a result, mRNA and protein expression of Notch 1 was significantly inhibited by the treatment of Notch 1-specific siRNA compared with the control, and the inhibition was dose-dependent. Notch 1 mRNA expression exhibited a 38.0\% ( $\mathrm{P}<0.05), 53.8 \%$ $(\mathrm{P}<0.01)$ and $70.4 \%(\mathrm{P}<0.01)$ decrease in $786-\mathrm{O}$ cells treated with 40, 80 and $120 \mathrm{nmol} / 1$ Notch 1 -specific siRNA compared with in those treated with negative control siRNA, respectively
Table II. Notch 1 protein expression was associated with the occurrence of CCRCC.

\begin{tabular}{|c|c|c|c|c|c|}
\hline \multirow[b]{2}{*}{ Group } & \multirow{2}{*}{$\begin{array}{l}\text { Patients, } \\
\mathrm{n}\end{array}$} & \multicolumn{2}{|c|}{$\begin{array}{l}\text { Notch } 1 \text { protein } \\
\text { expression, } \mathrm{n}(\%)\end{array}$} & \multirow[b]{2}{*}{$\chi^{2}$} & \multirow[b]{2}{*}{ P-value } \\
\hline & & Positive & Negative & & \\
\hline CCRCC & 52 & $43(82.7)$ & $9(17.3)$ & & \\
\hline Pericarcinoma & 47 & $20(42.6)$ & $27(57.4)$ & 17.188 & $<0.01$ \\
\hline Normal & 30 & $5(16.7)$ & $25(83.3)$ & 34.170 & $<0.01$ \\
\hline
\end{tabular}

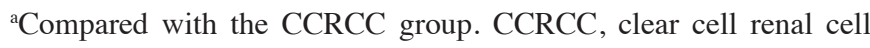
carcinoma.

Table III. Clinical significance of Notch 1 protein expression in clear cell renal cell carcinoma cases $(n=43)$.

\begin{tabular}{|c|c|c|c|c|}
\hline \multirow[b]{2}{*}{ Group } & \multicolumn{2}{|c|}{$\begin{array}{l}\text { Notch } 1 \text { protein } \\
\text { expression, n }(\%)\end{array}$} & \multirow[b]{2}{*}{$\chi^{2}$} & \multirow[b]{2}{*}{ P-value } \\
\hline & Low & High & & \\
\hline Sex & & & 0.036 & $>0.05$ \\
\hline Male & $8(18.6)$ & $21(48.9)$ & & \\
\hline Female & 5 (11.6) & $9(20.9)$ & & \\
\hline Age & & & 0.054 & $>0.05$ \\
\hline$<60$ years & $9(20.9)$ & 18 (41.9) & & \\
\hline$\geq 60$ years & $4(9.3)$ & $12(27.9)$ & & \\
\hline $\begin{array}{l}\text { Tumor-node- } \\
\text { metastasis stage }\end{array}$ & & & 6.267 & $<0.05$ \\
\hline $\mathrm{I}+\mathrm{II}$ & $11(25.6)$ & $13(30.2)$ & & \\
\hline III+IV & $2(4.7)$ & $17(39.5)$ & & \\
\hline Fuhrman grade & & & 7.900 & $<0.01$ \\
\hline $1+2$ & $12(27.9)$ & $14(32.6)$ & & \\
\hline $3+4$ & $1(2.3)$ & $16(37.2)$ & & \\
\hline Tumor size & & & 4.160 & $<0.05$ \\
\hline$<5.0 \mathrm{~cm}$ & $7(17.1)$ & 7 (17.1) & & \\
\hline
\end{tabular}

(Fig. 2B). Notch 1 protein expression exhibited a reduction of $37.4 \%(\mathrm{P}<0.05), 65.7 \%(\mathrm{P}<0.01)$ and $87.9 \%(\mathrm{P}<0.01)$, respectively, in the three Notch 1 siRNA-treated 786-O cells compared with the control (Fig. 2C). Therefore, the Notch 1-specific siRNA was successfully transfected into 786-O cells and dose-dependently inhibited the expression of Notch 1.

Inhibition of Notch 1 expression inhibits cell proliferation and induces cell apoptosis accompanied with decreased Bcl-2 and procaspase-3 expression in CCRCC 786-O cells. The effect of Notch 1 siRNA on the proliferation of CCRCC 786-O cells was evaluated by MTT assays. For 786-O cells treated with 40, 60, 80, 100 and $120 \mathrm{nmol} / 1$ Notch 1 siRNA, the cell proliferation rate was $84.7 \pm 5.5,66.6 \pm 3.2,52.4 \pm 4.5$, $31.2 \pm 2.4$ and $20.5 \pm 2.9 \%$, respectively, suggesting a $15.2 \%$ $(\mathrm{P}>0.05), 33.3 \%(\mathrm{P}<0.05), 47.6 \% \quad(\mathrm{P}<0.01), 68.8 \% \quad(\mathrm{P}<0.01)$ 
A

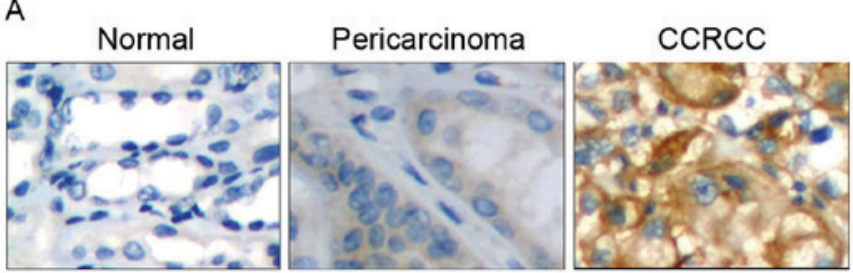

B

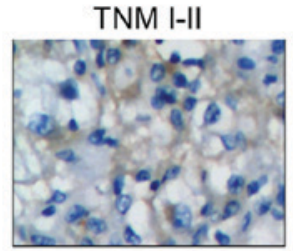

Fuhrman 1-2

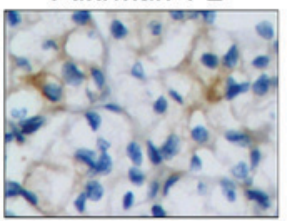

Figure 1. Notch 1 expression was positively associated with CCRCC carcinogenesis and progression. Notch 1 expression in renal tissues was detected with tissue microarray-based immunohistochemistry assays (magnification, x200). Stain used in this process was 3,3-diaminobenzidene (DAB) (A) Representative results of Notch 1 expression in normal, pericarcinoma and CCRCC renal tissues. (B) Representative results of Notch 1 expression in CCRCC tissues with different TNM stages. (C) Representative results of Notch 1 expression in CCRCC tissues with different Fuhrman grades. CCRCC, clear cell renal cell carcinoma; TNM, tumor-node-metastasis.

and $79.4 \%(\mathrm{P}<0.01)$ decrease compared with that of control siRNA-treated 786-O cells $(99.8 \pm 3.47 \%)$ (Fig. 3A). This indicated that Notch 1 siRNA dose-dependently suppressed the proliferation of 786-O cells. However, in the TUNEL assays, 786-O cells treated with 40,80 and $120 \mathrm{nmol} / \mathrm{l}$ Notch 1 siRNA exhibited a marked dose-dependent increase in cell apoptotic rate, which was $21.5 \pm 4.8,32.3 \pm 3.5$ and $46.3 \pm 4.7 \%$, respectively, and was $2.8-(\mathrm{P}<0.01), 4.2-(\mathrm{P}<0.01)$ and $6.1-(\mathrm{P}<0.01)$ fold higher compared with the control siRNA-treated 786-O cells (Fig. 3B). Representative results are presented in Fig. 3C. This demonstrated that Notch 1 siRNA dose-dependently induced apoptosis in 786-O cells. Together, these findings indicated that inhibition of Notch 1 expression could inhibit cell proliferation and induce cell apoptosis in 786-O cells. To identify the underlying molecular mechanisms, the alterations of two important apoptosis-associated molecules, Bcl-2 and procaspase-3, were investigated by western blot analysis. Bcl-2 is an anti-apoptotic protein and procaspase-3 is an anti-apoptotic effector (8). In the present study, Bcl-2 expression exhibited $25.0 \%(\mathrm{P}<0.05), 47.5 \%(\mathrm{P}<0.01)$ and $77.5 \%(\mathrm{P}<0.01)$ reduction in the Notch1 siRNA-treated $(40$, 80 and $120 \mathrm{nmol} / \mathrm{l}) 786-\mathrm{O}$ cells compared with the control siRNA-treated 786-O cells, respectively (Fig. 3D and E). In addition, procaspase-3 expression significantly decreased by $29.3 \%(\mathrm{P}<0.05), 56.0 \%(\mathrm{P}<0.01)$ and $81.3 \%(\mathrm{P}<0.01)$ in the three Notch1 siRNA-treated 786-O cells compared with the control, respectively (Fig. 3D and E). The aforementioned findings indicated that Notch 1 was involved in the regulation of cell proliferation and apoptosis in 786-O cells.
A
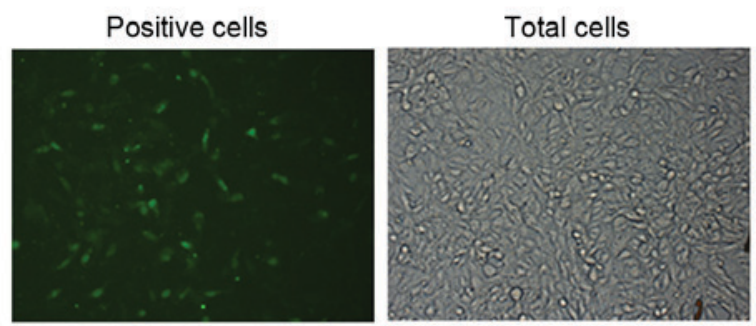

B

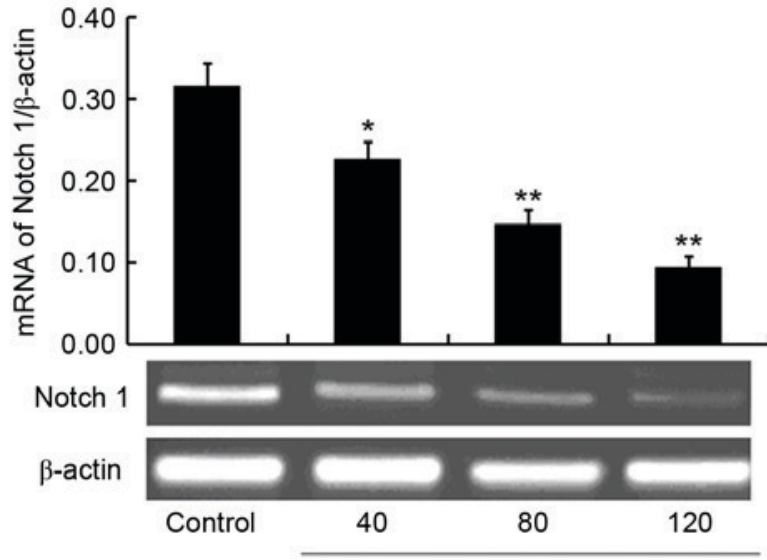

C

Concentration of Notch 1 siRNA (nmol/l)

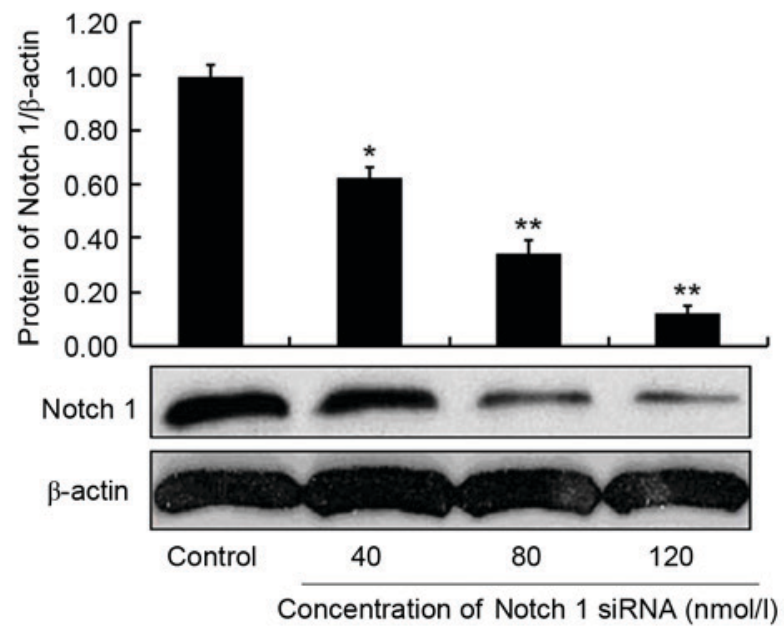

Figure 2. siRNA against Notch 1 was successfully transfected into clear cell renal cell carcinoma 786-O cells and inhibited the mRNA and protein expression of Notch 1. (A) A random sequence marked with fluorescence was transfected into 786-O cells as the parallel. Positive cells were detected under an inverted fluorescence microscope and total 786-O cells were observed at the same visual field of the microscope (magnification, $\mathrm{x} 200$ ). At $24 \mathrm{~h}$ post-transfection with Notch 1-specific siRNA and negative control siRNA, (B) mRNA and (C) protein expression of Notch 1 in 786-O cells was detected by reverse transcription-polymerase chain reaction and western blot analysis, respectively. The mRNA and protein expression of Notch 1 in 786-O cells was dose-dependently inhibited by increasing concentrations of Notch 1-specific-siRNA (40, 80 and $120 \mathrm{nmol} / \mathrm{l})$ compared with the control. ${ }^{*} \mathrm{P}<0.05,{ }^{* *} \mathrm{P}<0.01$ vs. control. siRNA, small interfering RNA.

Inhibition of Notch 1 expression inactivates Akt/mTOR signaling in CCRCC 786-O cells. To elucidate the molecular mechanism underlying Notch 1-mediated cell survival and proliferation in 786-O cells, alterations of the Akt/mTOR pathway were monitored. Akt, p-Akt, p-mTOR and p-P70 ribosomal S6-kinase (P70S6K) are the important components of the Akt/mTOR pathway (20) and their protein expression 
A

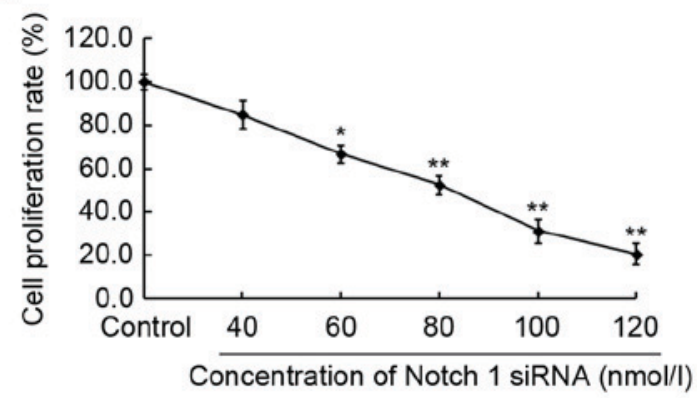

C

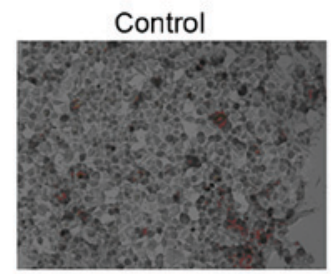

D

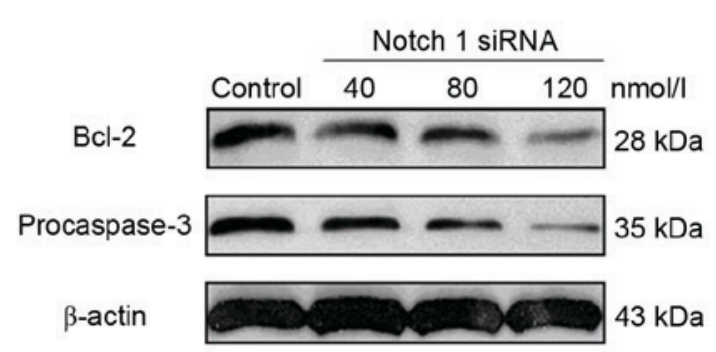

B

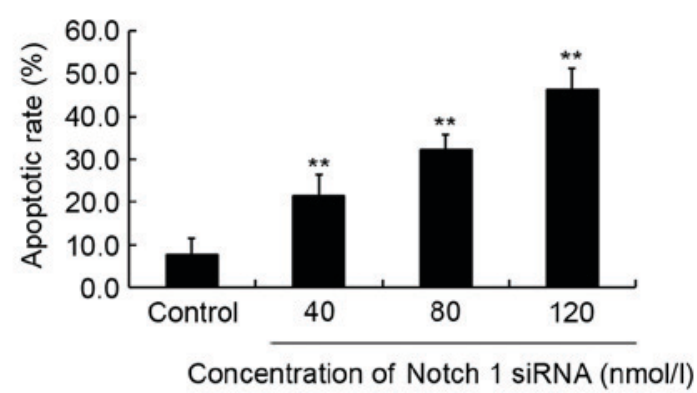

$80 \mathrm{nmol} / \mathrm{l}$

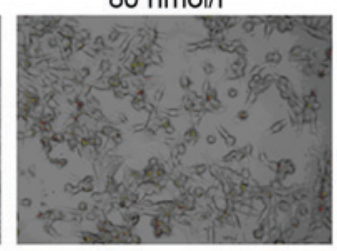

$120 \mathrm{nmol} / \mathrm{l}$

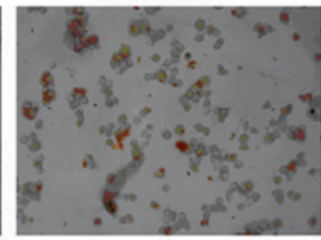

E

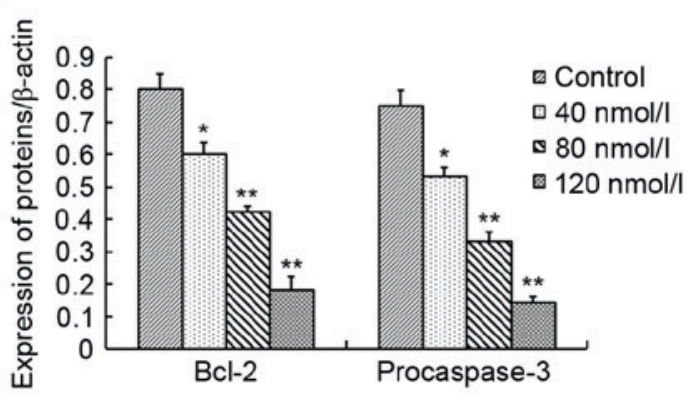

Figure 3. Inhibition of Notch 1 expression with Notch 1-specific-siRNA inhibited cell proliferation and induced cell apoptosis in clear cell renal cell carcinoma 786-O cells compared with decreased Bcl-2 and procaspase-3 expression. (A) Cell proliferation of 786-O cells exhibited a dose-dependent decrease following treatment with the increasing concentrations of Notch 1-specific-siRNA. (B) Cell apoptosis of 786-O cells suggested a dose-dependent increase following treatment with increasing concentrations of Notch 1-specific-siRNA. (C) Representative results of TUNEL assays on cell apoptosis under the microscope (magnification, x200). (D) Bcl-2 and procaspase-3 expression was dose-dependently reduced by increasing concentrations of Notch 1-specific-siRNA in 786-O cells. (E) Quantitative determination of Bcl-2 and procaspase-3 expression following normalization by $\beta$-actin. Data are presented as the mean \pm standard deviation of three independent western blot analyses and presented as a column diagram. ${ }^{*} \mathrm{P}<0.05,{ }^{* *} \mathrm{P}<0.01 \mathrm{vs}$. control. siRNA, small interfering RNA; Bcl-2, B-cell lymphoma-2.

was investigated in 786-O cells following treatment with Notch 1 siRNA (at the concentrations of 40,80 and $120 \mathrm{nmol} / \mathrm{l}$ ) and control siRNA. No significant differences were identified between the Akt levels in Notch 1 siRNA-treated 786-O cells compared with control siRNA-treated 786-O cells, whereas p-Akt, p-mTOR and p-P70S6K expression exhibited a dose-dependent decrease in Notch 1 siRNA-treated 786-O cells compared with the control. The decrease was $65.8 \%(\mathrm{P}<0.01)$, 76.3\% $(\mathrm{P}<0.01)$ and $89.5 \%(\mathrm{P}<0.01)$ for $\mathrm{p}-\mathrm{Akt}, 18.4 \%(\mathrm{P}>0.05)$, $46.9 \%(\mathrm{P}<0.01)$ and $75.5 \%(\mathrm{P}<0.01)$ for $\mathrm{p}-\mathrm{mTOR}$, and $40.0 \%$ $(\mathrm{P}<0.05), 71.4 \%(\mathrm{P}<0.01)$ and $88.6 \%(\mathrm{P}<0.01)$ for $\mathrm{p}-\mathrm{P} 70 \mathrm{~S} 6 \mathrm{~K}$ at 40, 80 and 120 nmol/l Notch 1 siRNA, respectively (Fig. 4). These findings demonstrated that inhibition of Notch 1 expression could suppress the activity of the Akt/mTOR signaling pathway in 786-O cells.

\section{Discussion}

At present, the global incidence of RCC is increasing year by year, and no therapeutic strategies can completely cure the disease, particularly advanced RCC $(2,5)$. Targeted therapy has been proposed to overcome the difficulty due to the gradually revealed molecular mechanisms underlying RCC development (5). Several molecules have been identified as the potential therapeutic targets of RCC, including VEGF and mTOR (21). The present study investigated the potential of Notch 1 as a target of CCRCC treatment. The results demonstrated that Notch 1 protein expression was associated with CCRCC carcinogenesis and progression. Therefore Notch 1 may be a valuable target for CCRCC treatment.

The Notch signaling pathway is a highly-conserved regulator in mediating cell to cell interactions (3). It, together with numerous other signaling pathways, composes a complicated signaling network to precisely regulate multiple biological processes, including cell growth, differentiation and apoptosis (22). Notch 1 is an essential component of this pathway and may perform a vital role in these biological processes (3). In the present study, Notch 1 protein expression in CCRCC tumor, pericarcinoma and normal renal tissues was compared and the results demonstrated that Notch 1 protein expression was closely associated with CCRCC carcinogenesis. In addition, patients with higher TNM stage or Fuhrman grade or larger tumor size exhibited higher Notch 1 protein expression, indicating that Notch 1 protein was positively correlated 
A

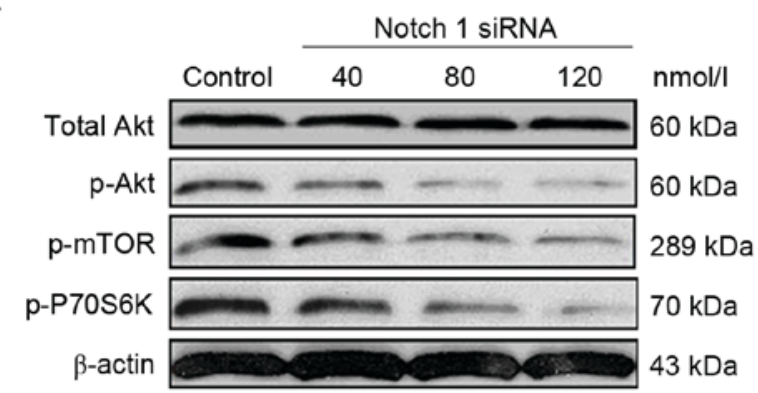

B

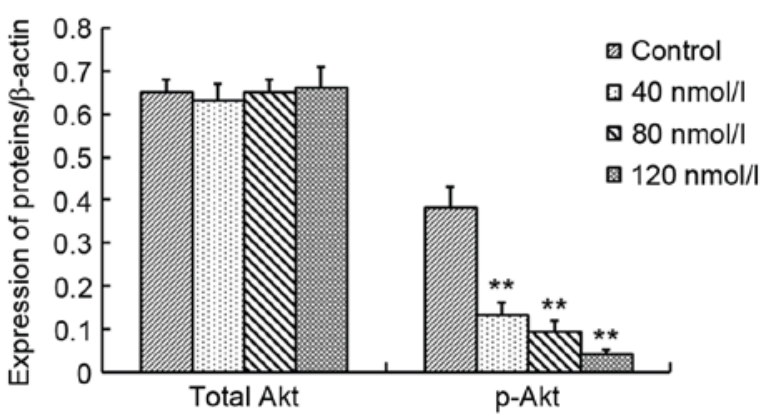

C

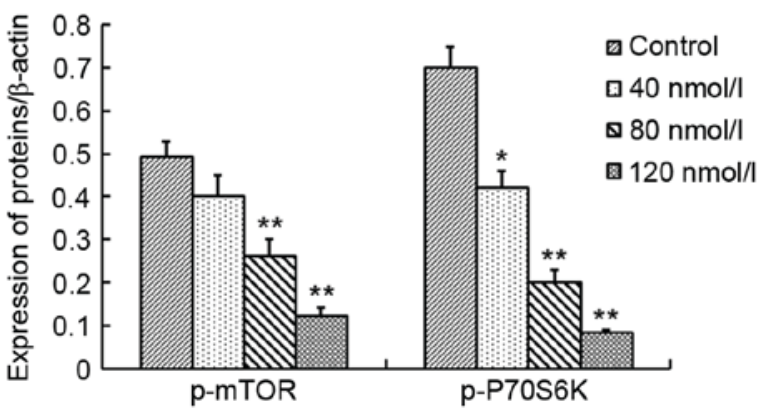

Figure 4. Inhibition of Notch 1 expression with Notch 1-specific-siRNA suppressed the activity of the Akt/mTOR signaling pathway in clear cell renal cell carcinoma 786-O cells. Expression of key components in the Akt/mTOR signaling pathway was evaluated by western blot analysis. (A) Inhibition of Notch 1 expression had no effect on total Akt expression, but inhibited the expression of p-Akt, p-mTOR and p-P70S6K in a dose-dependent manner Quantitative determination of (B) Akt and p-Akt, and (C) p-mTOR and p-P70S6K expression following normalization by $\beta$-actin. Data are presented as the mean \pm standard deviation of three independent western blot assays and presented as column diagrams. ${ }^{*} \mathrm{P}<0.05,{ }^{* *} \mathrm{P}<0.01$ vs. control. siRNA, small interfering RNA; mTOR, mechanistic target of rapamycin; p-, phosphorylated-.

with CCRCC progression. On this basis, it was hypothesized Notch 1 may be a potential target for CCRCC therapy.

To confirm the aforementioned hypothesis, the effect of Notch 1 on cell proliferation and apoptosis was examined by silencing Notch 1 expression in CCRCC 786-O cells in vitro. Following the interference of Notch 1 expression with increasing concentrations of Notch 1-specific siRNA, 786-O cells exhibited a dose-dependent decrease in proliferation and a dose-dependent increase in apoptosis accompanied with a dose-dependent decrease in expression of Bcl-2 and procaspase-3. These findings demonstrated that Notch 1 was involved in the regulation of cell survival and proliferation in CCRCC 786-O cells, which was consistent with previous studies on other cancers, including glioma, leukemia and pancreatic cancers (23-25). Bcl-2 is a key anti-apoptotic protein and usually acts as the switch of cell apoptosis (26). If Bcl-2 expression is downregulated, cells switch to the apoptotic process, or else to the anti-apoptotic process. Procaspase- 3 is an anti-apoptotic effector. When cells switch to the apoptotic process, procaspase-3 will be cleaved into active capspase-3, which subsequently induces the caspase cascades to facilitate cell apoptosis. Conversely, when cells switch to the anti-apoptotic process, procaspase-3 will be accumulated in cells (8). In the present study, Bcl-2 and procaspase- 3 expression exhibited a marked dose-dependent decrease in 786-O cells following treatment with increasing concentrations of Notch 1-specific siRNA, which indicated that inhibition of Notch 1 by Notch 1 siRNA downregulated the Bcl-2 expression, resulting in the initiation of apoptotic process and the cleavage of procaspase-3, and ultimately leading to apoptosis in 786-O cells. In this regard, Notch 1 was a potential target against cell survival and proliferation for CCRCC 786-O cells.

To confirm the potential of Notch 1 as the therapeutic target in CCRCC, the underlying molecular mechanism that Notch 1 may be involved in during CCRCC development was investigated. It has been demonstrated that the Akt/mTOR signaling pathway performs a central role in mediating cell cycle and apoptosis signaling and is implicated in Notch 1-mediated cell survival and proliferation in glioma $(27,28)$. Akt, also termed protein kinase $\mathrm{B}$, is a serine/threonine protein kinase and could be phosphorylated by phosphatidylinositol 3-kinase (8). A previous study demonstrated that $\mathrm{p}$-Akt could upregulate Bcl-2 through cyclic AMP response element binding protein to inhibit cell apoptosis (29). In the present study, p-Akt expression was inhibited in a dose-dependent manner in 786-O cells by the treatment of increasing concentrations of Notch 1 siRNA, while the total Akt expression was not affected, suggesting that Notch 1 siRNA could inhibit Akt phosphorylation, which thereby reduced the activity of the Akt signaling pathway and contributed to cell apoptosis. This was consistent with previous studies $(27,30)$. mTOR is an important downstream effector of the Akt signaling pathway and also is a crucial target for RCC therapy (31). It has been indicated that phosphorylated mTOR could induce cell cycle transition between the $G_{1}$ and $S$ phase to facilitate cell proliferation and control protein synthesis through the regulation of P70S6K $(20,32)$. In the present study, it was revealed that protein expression of p-mTOR and p-P70S6K exhibited a marked dose-dependent decrease along with dose-dependently decreased p-Akt in the Notch 1-specific siRNA-treated 786-O cells. Together, the findings from the present study demonstrated that the inhibition of Notch 1 expression by Notch 1-specific siRNA inactivated Akt/mTOR signaling, inhibited cell proliferation and induced cell apoptosis in 786-O cells. This is consistent with the result in a previous study by Mungamuri et al (33) on T-cell acute lymphocyte leukemia. Collectively, the present study confirmed that Notch 1 was involved in the regulation of cell survival and proliferation in 786-O cells through the Akt/mTOR signaling-dependent pathway, and Notch 1 was a valuable target for CCRCC treatment.

In summary, association analysis results from the present study demonstrated that Notch 1 expression was closely associated with CCRCC carcinogenesis and progression. In addition, inhibition of Notch 1 expression inhibited cell proliferation and induced cell apoptosis in CCRCC 786-O cells, suggested that Notch 1 was involved in CCRCC development. Furthermore, 
treatment with Notch 1-specific siRNA decreased expression of Bcl-2 and procaspase-3 in a dose-dependent manner in CCRCC 786-O cells, which was accompanied with a dose-dependent decrease in the expression of p-Akt, p-mTOR and $\mathrm{p}-\mathrm{P} 70 \mathrm{~S} 6 \mathrm{~K}$. This indicated that Notch 1 was involved in the regulation of cell survival and proliferation in 786-O cells through the Akt/mTOR signaling-dependent pathway. Due to the complexity of cancer-associated cell proliferation and apoptosis, the underlying molecular mechanisms are not limited to the aforementioned findings. However, these findings confirmed that Notch 1 is a valuable target against cell survival and proliferation in CCRCC, and Notch 1-specific siRNAs may be developed as target agents to be used as single agents or in combination with other chemotherapeutics in CCRCC treatment.

\section{Acknowledgements}

The present study was supported by the Natural Science Foundation of Fujian Province (grant no. 2013J01393).

\section{References}

1. Cohen HT and McGovern FJ: Renal-cell carcinoma. N Engl J Med 353: 2477-2490, 2005.

2. Ljungberg B, Campbell SC, Choi HY, Jacqmin D, Lee JE, Weikert S and Kiemeney LA: The epidemiology of renal cell carcinoma. Eur Urol 60: 615-621, 2011.

3. Sjölund J, Johansson M, Manna S, Norin C, Pietras A, Beckman S, Nilsson E, Ljungberg B and Axelson H: Suppression of renal cell carcinoma growth by inhibition of Notch signaling in vitro and in vivo. J Clin Invest 118: 217-228, 2008.

4. Athar U and Gentile TC: Treatment options for metastatic renal cell carcinoma: A review. Can J Urol 15: 3954-3966, 2008.

5. Randall JM, Millard F and Kurzrock R: Molecular aberrations, targeted therapy, and renal cell carcinoma: Current state-of-the-art. Cancer Metastasis Rev 33: 1109-1124, 2014.

6. Holland WS, Tepper CG, Pietri JE, Chinn DC, Gandara DR, Mack PC and Lara PN Jr: Evaluating rational non-cross-resistant combination therapy in advanced clear cell renal cell carcinoma: Combined mTOR and AKT inhibitor therapy. Cancer Chemother Pharmacol 69: 185-194, 2012.

7. Ramp U,Caliskan E, Mahotka C, Krieg A,Heikaus S, Gabbert HE and Gerharz CD: Apoptosis induction in renal cell carcinoma by TRAIL and gamma-radiation is impaired by deficient caspase-9 cleavage. Br J Cancer 88: 1800-1807, 2003.

8. Wu WK, Wang XJ, Cheng AS, Luo MX, Ng SS, To KF, Chan FK, Cho $\mathrm{CH}$, Sung JJ and Yu J: Dysregulation and crosstalk of cellular signaling pathways in colon carcinogenesis. Crit Rev Oncol Hematol 86: 251-277, 2013.

9. Bolós V, Grego-Bessa J and de la Pompa JL: Notch signaling in development and cancer. Endocr Rev 28: 339-363, 2007.

10. Wang Z, Li Y, Ahmad A, Banerjee S, Azmi AS, Kong D, Wojewoda C, Miele L and Sarkar FH: Down-regulation of Notch-1 is associated with Akt and FoxM1 in inducing cell growth inhibition and apoptosis in prostate cancer cells. J Cell Biochem 112: 78-88, 2011.

11. Ai Q, Ma X, Huang Q, Liu S, Shi T, Zhang C, Zhu M, Zhang Y, Wang B, Ni D, et al: High-level expression of Notch1 increased the risk of metastasis in T1 stage clear cell renal cell carcinoma. PLoS One 7: e35022, 2012.

12. Liu S, Ma X, Ai Q, Huang Q, Shi T, Zhu M, Wang B and Zhang X: NOTCH1 functions as an oncogene by regulating the PTEN/PI3K/AKT pathway in clear cell renal cell carcinoma. Urol Oncol 31: 938-948, 2013.
13. Terrone C, Cracco C, Porpiglia F, Bollito E, Scoffone C, Poggio M, Berruti A, Ragni F, Cossu M, Scarpa RM and Rossetti SR: Reassessing the current TNM lymph node staging for renal cell carcinoma. Eur Urol 49: 324-331, 2006.

14. Wan F, Zhu Y, Han C, Xu Q, Wu J, Dai B, Zhang H, Shi G, $\mathrm{Gu} \mathrm{W}$ and Ye D: Identification and validation of an eight-gene expression signature for predicting high Fuhrman grade renal cell carcinoma. Int J Cancer 140: 1199-1208, 2017.

15. Cai L, Ma X, Huang Y, Zou Y and Chen X: Aberrant histone methylation and the effect of Suv39H1 siRNA on gastric carcinoma. Oncol Rep 31: 2593-2600, 2014.

16. Masuda S, Kumano K, Shimizu K, Imai Y, Kurokawa M, Ogawa S, Miyagishi M, Taira K, Hirai H and Chiba S: Notch1 oncoprotein antagonizes TGF-beta/Smad-mediated cell growth suppression via sequestration of coactivator p300. Cancer Sci 96: 274-282, 2005.

17. Amarzguioui M and Prydz $\mathrm{H}$ : An algorithm for selection of functional siRNA sequences. Biochem Biophys Res Commun 316: 1050-1058, 2004.

18. Ui-Tei K, Naito Y, Takahashi F, Haraguchi T, Ohki-Hamazaki H, Juni A, Ueda R and Saigo K: Guidelines for the selection of highly effective siRNA sequences for mammalian and chick RNA interference. Nucleic Acids Res 32: 936-948, 2004.

19. Reynolds A, Leake D, Boese Q, Scaringe S, Marshall WS and Khvorova A: Rational siRNA design for RNA interference. Nat Biotechnol 22: 326-330, 2004.

20. Inoki K, Corradetti MN and Guan KL: Dysregulation of the TSC-mTOR pathway in human disease. Nat Genet 37: 19-24, 2005.

21. Vano YA, Tartour E, Fournier LS, Beuselinck B, Mejean A and Oudard S: Prognostic factors in patients with advanced renal cell carcinoma treated with VEGF-targeted agents. Expert Rev Anticancer Ther 14: 523-542, 2014.

22. Maillard I and Pear WS: Notch and cancer: Best to avoid the ups and downs. Cancer Cell 3: 203-205, 2003.

23. Yao J, Zheng K, Li C, Liu H and Shan X: Interference of Notch1 inhibits the growth of glioma cancer cells by inducing cell autophagy and down-regulation of Notch1-Hes-1 signaling pathway. Med Oncol 32: 610, 2015.

24. Grabher C, von Boehmer $\mathrm{H}$ and Look AT: Notch 1 activation in the molecular pathogenesis of T-cell acute lymphoblastic leukaemia. Nat Rev Cancer 6: 347-359, 2006.

25. Kunnimalaiyaan S, Trevino J, Tsai S, Gamblin TC and Kunnimalaiyaan M: Xanthohumol-mediated suppression of Notch1 signaling is associated with antitumor activity in human pancreatic cancer cells. Mol Cancer Ther 14: 1395-1403, 2015.

26. Chen C, Cui J, Zhang W and Shen P: Robustness analysis identifies the plausible model of the Bcl-2 apoptotic switch. FEBS Lett 581: 5143-5150, 2007.

27. Zhao N, Guo Y, Zhang M, Lin L and Zheng Z: Akt-mTOR signaling is involved in Notch-1-mediated glioma cell survival and proliferation. Oncol Rep 23: 1443-1447, 2010.

28. Sangphech N, Osborne BA and Palaga T: Notch signaling regulates the phosphorylation of Akt and survival of lipopolysaccharide-activated macrophages via regulator of $\mathrm{G}$ protein signaling 19 (RGS19). Immunobiology 219: 653-660, 2014.

29. Pugazhenthi S, Nesterova A, Sable C, Heidenreich KA, Boxer LM, Heasley LE and Reusch JE: Akt/protein kinase B up-regulates Bcl-2 expression through cAMP-response element-binding protein. J Biol Chem 275: 10761-10766, 2000.

30. Palomero T, Sulis ML, Cortina M, Real PJ, Barnes K, Ciofani M, Caparros E, Buteau J, Brown K, Perkins SL, et al: Mutational loss of PTEN induces resistance to NOTCH1 inhibition in T-cell leukemia. Nat Med 13: 1203-1210, 2007.

31. Cho D: Novel targeting of phosphatidylinositol 3-kinase and mammalian target of rapamycin in renal cell carcinoma. Cancer J 19: 311-315, 2013.

32. Bjornsti MA and Houghton PJ: The TOR pathway: A target for cancer therapy. Nat Rev Cancer 4: 335-348, 2004.

33. Mungamuri SK, Yang X, Thor AD and Somasundaram K: Survival signaling by Notch1: Mammalian target of rapamycin (mTOR)-dependent inhibition of p53. Cancer Res 66: 4715-4724, 2006. 